hour of its occurrence is identical with that of the appearance of the phenomenon seen by me, and the day of the month so closely approximates as to be only one day later. That which Dr. Armstrong saw in 1842 was at the time of the full moon in February.

C. POOLEY

\section{Curious Habit of a Brazilian Moth}

At the last meeting of the Literary and Philosophical Society of Liverpool (April 30) I read the following note on a remarkable habit of a Brazilian moth; and as it is a habit that has perhaps not been observed before, it may be of sufficient interest for insertion in NATURE.

The moth (of which I inclose a sketch) is a species of Panthera (P. Apardalaria).

When rambling about the rocky beds of small streams on the Serra da Contareira, near San Paulo, I have often been struck by the great numbers of yellow and black moths that flew up from the water as I disturbed them by my presence. On careful examination I found that these moths were resting upon the wet stones, in many cases even with a film of water flowing over the spot on which they had settled, and were all engaged in sucking up the water through the proboscis (I can hardly call it drinking, for no imaginable thirst could account for the enormous amount of water sucked up), and this water was passing through the moths, minute drops forming on the tip of the abdomen, and falling off as formed. I timed several specimens, and found that the average rate was fifty drops per minute. I have observed the same individu 1 remain in the same position with the action going on unceasingly for three hours ; and in all probability it had been there some time before I observed it, and remained after I went away. But even in this length of time the quantity of water passing through the moth was enormous in proportion to its size. The drops I did not actually measure, but they are probably between $\mathbf{I}$ and 2 millimetres in diameter. 'Taking them to be 1.5 millimetres in diameter, the total amount of water in the three hours was $15^{\circ} 84$ cubic centimetres, or almost exactly a cubic inch. This quantity is equal to about 200 times the volume of the body of the moth

The tibiæ of the hindlegs are very thick and are armed with long hairs, that by their capillary action prevent the moth being immersed in the water. I have often seen one of them knocked down by a little spurt of water splashing over the stone on which it was standing, and it recovered itself immediately without being wetted in the least.

Upon my return to Brazil I shall try to measure exac:ly the amount of water passing through one of these moths. And it would be most interesting to find out what is the object of this excessive drinking. Can it be that the moth extracis nourishment from minute particles of or sanic matter contained in the water?

I may remark that the water of the streams where I have observed the moth is very clear and pure.

E. DUKinfield Jones

Acrefield, Woolton, Liverpool, May 5

\section{Leaves and their Environment}

I TAKE the following from an experiment which I made two years ago. I think it throws some light on the point under discussion :-

On May 8 six young pea plants, similar in size, \&c., were transplanted from the garden into three large flowerpots, a pair in each, and were covered with bell glasses. On next day an apparatus for generating a constant stream of carbonic acid gas was connected to No. I bell glass. No. 2 was left normal. No. 3 inclosed a small disk of caustic potash solution. They all had as nearly as possible the same amount of sunlight, and the same measured quantity of water was given to each.

Taking the notes referring to the leaves only I find on May 2I : "No. I, vigorous large leaves. No. 2, much smaller leaves. No. 3 , leaves smaller than No. 2 , with edges serrated as if the veins were growing on, but could not find food for fleshy part of leaf-really a starved plant."

On May 27 the plants were taken up and washed, when No. I weighed $\mathrm{r}_{48} 8$ grains; No. 2, 115.5 grains; and No. 3,87 grains. After drying, the weights of Nos. I and 3 were as 19 to 13 . The longest leaf on No. I measured $1 \frac{5}{3} \mathrm{in}$., and on No. 3 $1 \frac{1}{8}$ in.

J. BROWN

\section{Foam Balls}

In Nature, vol. xxvii. p. 53I, there is a mention by Mr. J. Rand Capron of foam ball: These are common on the coast of the Northern United States, especially of a cold dry day, when, if there be much wind, these huge foam balls, which may reach a diameter of two feet or more, are rolled up the beach. Their weight soon changes their form, so that at last they present the appearance of long white rolls of sparkling foam. This singular appearance was first described in verse, so far as I know, by Dr. S. Weir Mitchell, of Philadelphia. The verse, as I recall it-I quote from memory-is this :-

\section{"And wilder yet when of a winter day}

The cold dry norther rolls athwart the beach

The gleaming foam balls into serpents white,

Philadelphia, U.S.

An American Subscriber

\section{ANTHROPOLOG $Y^{1}$}

II.

$\mathrm{N}$ considering the claims of anthropology as a practical means of understanding ourselves, our own thoughts and ways, we have to form an opinion how the ideas and arts of any people are to be accounted for as developed from preceding stages. To work out the lines along which the process of organisation has actually moved, is a task needing caution and reserve. A tribe may have some art which plainly shows progress from a ruder state of things, and yet it may be wrong to suppose this development to have taken place among themselves-it may be an item of higher culture that they have learnt from sight of a more advanced nation. Our own history shows to how small an extent we have been the developers of our own arts and sciences, how largely we have embodied the culture of other nations. It is essential in studying even savage and barbaric culture, to allow for borrowing, so as to clear the lines of real development. When the savage comes into contact with the civilised man, he does not see his way to copy all the high contrivances of this mysterious higher being, but where be thinks he can imitate, he is apt to try, and sometimes succeeds, though oftener fails. After a time of friendly intercourse, the wild man generally learns such substantial secrets of culture as he is in a position to assimilate. Ethnologists have been inclined to look on the wandering Esquimaux of the polar regions as "nature-men," and perhaps no harm has arisen from reasoning on them as such, for they are in many ways fair representatives of the rude nomad hunter and fisher. But I suspect that in some respects they do not show the mere result of the primitive savage working out by slow degrees a somewhat higher culture. Looking at them not as they are now, Europeanised under missionary training, but as they were when Egede and Cranz went out to them from Denmark in the eighteenth century, it seems that their way of life even then had some incidents above the savage level. Their clothing was artistically contrived to resist the intense cold. Its material is sometimes strange to cur notions; an undershirt of birds' skins with the feathers inside requires an effort to realise even in our bleakest season. But a leather tunic with sleeves and a hood to pull over the head, a pair of sealskin breeches with leather stockings and boots, form a defence against the cold, at once like that familiar to Europeans, and unlike any unquestionable savage costume, such as the furs which in the Antarctic regions the shivering Fuegians throw over their shoulders. Moreover, all across the polar coast region of the Esquimaux their houses of earth or moulded snow, with compartments like ship-cabins, are warmed and lighted with blubber, burnt in lamps shaped out of potstone with moss to serve as wick, and over these are hung the potstone kettles for their slight cookery. Now,

" Two lectures on "Anthropology," delivered on February 15 and 21 at the University Museum, Oxford, by E. B. Tylor, D.C.L., F.R.S. Continued from p. II. 